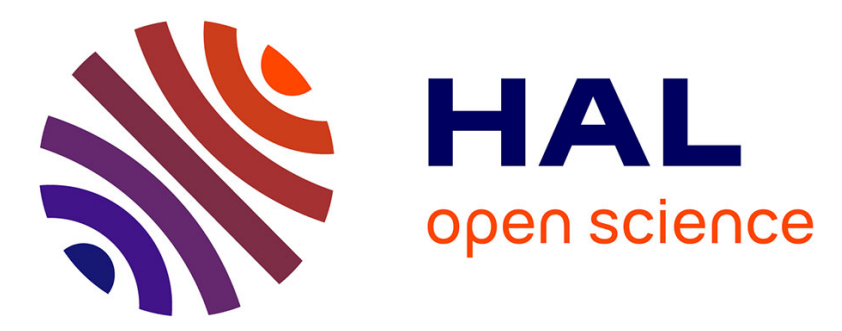

\title{
Electropneumatic Cylinder Backstepping Position Controller Design With Real-Time Closed-Loop Stiffness and Damping Tuning
}

Frédéric Abry, Xavier Brun, Sylvie Sesmat, Eric Bideaux, Christophe Ducat

\section{- To cite this version:}

Frédéric Abry, Xavier Brun, Sylvie Sesmat, Eric Bideaux, Christophe Ducat. Electropneumatic Cylinder Backstepping Position Controller Design With Real-Time Closed-Loop Stiffness and Damping Tuning. IEEE Transactions on Control Systems Technology, 2016, 24 (2), pp.541 - 552. 10.1109/TCST.2015.2460692 . hal-01873411

\section{HAL Id: hal-01873411 https://hal.science/hal-01873411}

Submitted on 24 Apr 2019

HAL is a multi-disciplinary open access archive for the deposit and dissemination of scientific research documents, whether they are published or not. The documents may come from teaching and research institutions in France or abroad, or from public or private research centers.
L'archive ouverte pluridisciplinaire HAL, est destinée au dépôt et à la diffusion de documents scientifiques de niveau recherche, publiés ou non, émanant des établissements d'enseignement et de recherche français ou étrangers, des laboratoires publics ou privés.

$$
\text { Copyright }
$$




\title{
Electro-pneumatic cylinder backstepping position controller design with real time closed-loop stiffness and damping tuning
}

\author{
Abry Frédéric, Brun Xavier, Sesmat Sylvie, Bideaux Éric and Ducat Christophe
}

\begin{abstract}
This paper develops a backstepping based algorithm to control the position of an electro-pneumatic actuator while allowing the precise tuning of the closed-loop stiffness and damping. The proposed strategy offers an efficient method to choose the controller parameters based on a physical and linear analysis. The strict feedback form of the model, which is required in order to apply the backstepping methodology, is obtained through the use of a transformation of the system's inputs. The proposed MIMO control law as well as its parameters tuning method are validated experimentally. Experimental results are provided using an innovative test bench combining an electropneumatic cylinder and an electric linear motor. The two main contributions are, firstly, the use of a new decoupling transformation to control the system's two degrees of freedom and, secondly, the description of a closed-loop damping and stiffness tuning strategy. Simultaneous position and stiffness control results in a more precise and adjustable Variable Stiffness Actuator (VSA) than the simultaneous pneumatic force - stiffness control laws generally encountered in the literature. Moreover, a specific study is conducted to clarify the interaction between pneumatic and closed-loop stiffnesses in order to combine the advantages of passive and active compliant actuators.
\end{abstract}

Index Terms-Nonlinear control, backstepping controller design, electro-pneumatic actuator, stiffness control, damping control

\section{INTRODUCTION}

$\mathbf{P}$ OSItion control of linear actuators is a subject which has been widely addressed in the literature, for many different kinds of actuators technology. Still, most of the propositions made over the years tend to focus on the performances in terms of precision or rapidity: few deal with the issue of controlling the actuator's response to an external force disturbance. Assuming that a linear actuator is controlled to stay still or track a given position trajectory, when submitted to an external force, depending on the situation the objective can be to maintain a high stiffness (in order to reduce the steady state error) or to act in a compliant manner (to reduce the disturbance transmission to the rest of the system or prevent any danger for a human operator for instance). This closed-loop behavior should normally be described by the specifications and could even vary over time for a given system. Actuators fulfilling this requirements are generally referred to as compliant actuators or, more precisely, as Variable Stiffness Actuators (VSA).

VSA can be divided between passive and active ones [1]. Actuators of the first category basically contain an elastic element which can store energy while, on the other hand, active compliant actuators are stiff actuators which are controlled to behave as a spring (and, possibly, a damper) in closed-loop.
Passive solutions generally offer a good bandwidth (which is a critical property for shock absorption) and an excellent energy efficiency. On the other hand, most of the time, they show a very limited tuning range of both equilibrium position and closed-loop stiffness which, moreover, seldom can be modified in real-time.

Among the classical linear actuators, one of the most common is the electro-mechanical actuator (EMA) which is essentially an electric rotary motor of any technology which movement is transformed into a translation by means of a mechanical device such as a roller screw. Those actuators have many advantages but their very high inertia (due to the mechanical transformation of the movement) and resulting limited reversibility (the motor rotor will not necessarily turn when an external force is applied even if the latter is not generating any torque) often prevent their use when a compliant behavior is required. The main other electric linear actuators technology is the linear motor (which is similar to a rotary electric motor with the rotor and stator circular magnetic field components laid out in a straight line). The fact that those actuators have no mechanical transformation of the movement gives them very high dynamic performances and makes them fully reversible, thus making them perfect when an application requires to switch from a stiff to a compliant behavior. The main issue is that those actuators show absolutely no elastic behavior in open-loop. Therefore, their use as VSAs stricly relies on the control algorithm which tends to be energy-consuming and not very efficient for shock absorptions. Moreover they are still very expensive and therefore are generally not suited for industrial cost effective applications.

Fluid power actuators, which can be either hydraulic or pneumatic depending on the required force range, are significantly less expensive than the linear electrical motors while also having a significantly lower inertia than EMAs. This makes them good candidates for linear position control with adequate tuning of the closed-loop response. Moreover, unlike electric motors, they display a natural elastic behavior due to the fluid compressibility which can be used to achieve smooth shock absorption. Still, their strongly non-linear behavior (in the mathematical sense of the term this time) has so far prevented the synthesis of control algorithms allowing an user friendly tuning of the actuator response to an external disturbance.

In this study, the problem of adjusting the response to an external force disturbance in position control is studied for electro-pneumatic cylinders. These systems are recognized as 
cheap, clean and safe with a high power-to-weight ratio and dynamic response.

The use of servovalves allows to precisely control the mass flow rate of gas entering or exiting the cylinder's chamber and therefore makes smooth displacements of the piston possible.

Based on this architecture, the first control schemes [2], [3] were mostly based upon the linearization of the model around a given steady state. Subsequently, many non-linear position control strategies have been proposed: feedback linearization [4], sliding mode [5], [6], backstepping [7] and backstepping with friction compensation [8], [9]. Recently, some strategies described as stiffness control have been proposed [10], [11]. Yet, they only allow the control of the pneumatic stiffness of the actuator, which must not be mistaken for the closed-loop stiffness, and therefore propose a limited use of pneumatic actuators as VSAs.

A preliminary study [12] has introduced a control algorithm designed using an alternative state model of the cylinder and the backstepping theory. In this previous work, simulation results have shown that the closed-loop stiffness and damping can be successfully tuned. In this paper, an extension is proposed: 1)the control law is enhanced to avoid any closedloop stiffness bias that might be caused by a pneumatic force steady-state error, 2)the concepts of pneumatic stiffness and closed-loop stiffness are clearly defined and their interactions are studied rigorously to clarify the misconceptions frequently encountered in the literature, and 3)experimental results are provided using an innovative test bench and a protocol which actually demonstrate the importance of the closed-loop tuning.

\section{EleCtRo-PNEUMATIC ACTUATOR OVERVIEW}

The actuator (see Fig. 1 and Table I) used in this study is a compact ASCO Numatics double acting symmetric pneumatic cylinder. Each of its chambers is supplied by an independent servovalve (Festo MPYE 5 1/8 HF). In order to optimize the cylinder dynamics, a specific modification has been performed to directly connect each chamber to its servovalve thus greatly reducing pressure losses and possible leaks. A LVDT position sensor (MEAS DC-EC) has been added to measure the piston displacement and two miniature sensors are integrated to monitor the pressures in the cylinder chambers.

TABLE I

CYLINDER MAIN CHARACTERISTICS

\begin{tabular}{lll}
\hline \hline Quantity & Value & \\
\hline Total stroke & 50 & $\mathrm{~mm}$ \\
Piston diameter & 100 & $\mathrm{~mm}$ \\
Rod diameter & 28 & $\mathrm{~mm}$ \\
Piston effective section & 7238 & $\mathrm{~mm}^{2}$ \\
Maximum force at 7 bar & 4343 & $\mathrm{~N}$ \\
\hline \hline
\end{tabular}

The servovalves are supplied with air at 7 absolute bar through a pressure regulator and a 40 Liter buffer tank.

\section{MODEL FOR CONTROL SYNTHESIS}

\section{A. Model of the pressure dynamics}

In order to accurately describe the thermodynamical behavior of the cylinder, a model based on the fluid mass and energy
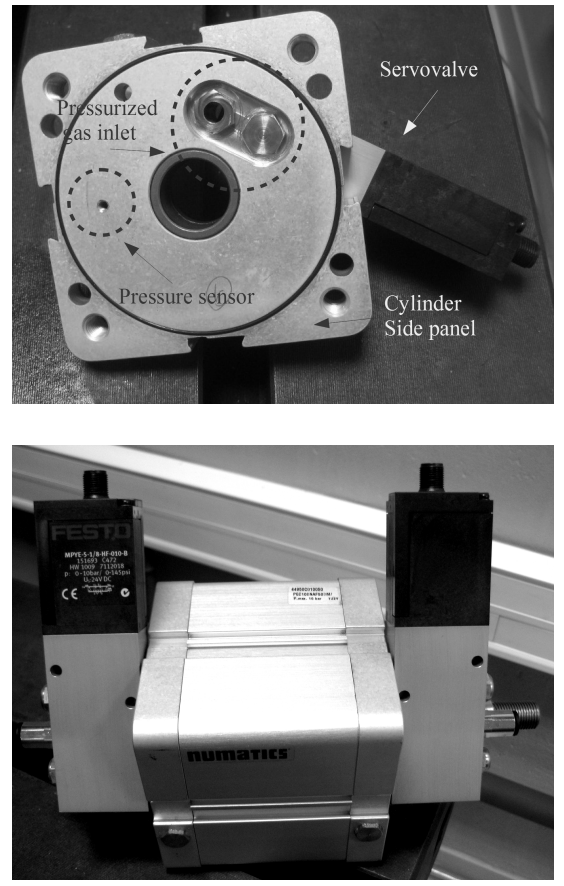

Fig. 1. Integration of the servovalves and pressure sensors in the cylinder

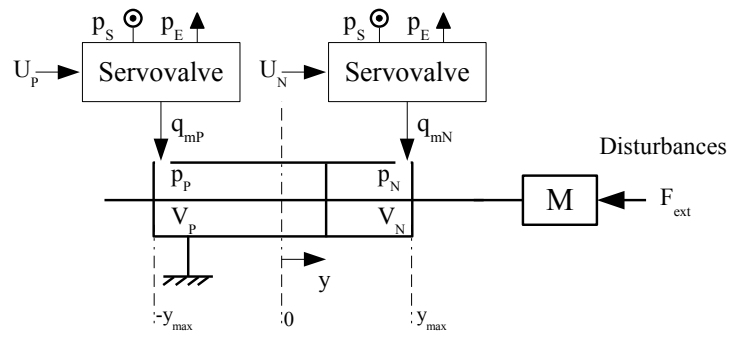

Fig. 2. Technological system under consideration

conservation laws and taking into account heat exchanges by convection is commonly used in the literature [13]. The latter is based on the following assumptions: 1)homogeneous temperature and pressure distributions in the chambers, 2)absence of leakage, 3)air is an ideal gas and 4)air kinetic and potential energies are negligible compared to internal energy. It leads to a high order model suitable for simulation purposes but which requires the temperatures measurement to be used as a control model. Thus, a simpler yet fairly accurate representation is generally chosen for control synthesis. The classical way to simplify the model is to adopt a polytropic law and consider the relative temperature variations in both chambers to be small and therefore negligible. This leads to the following reduced order model [14]:

$$
\left\{\begin{aligned}
\frac{d p_{P}}{d t} & =\frac{k r T}{V_{P}}\left(q_{m P}-\frac{S}{r T} p_{P} v\right) \\
\frac{d p_{N}}{d t} & =\frac{k r T}{V_{N}}\left(q_{m_{N}}+\frac{S}{r T} p_{N} v\right)
\end{aligned}\right.
$$

with $T$ the supply temperature, $r$ the specific ideal gas constant of air, $q_{m_{P}}$ and $q_{m_{N}}$ the mass flow rates defined as positive entering the chambers $\mathrm{P}$ and $\mathrm{N}$ respectively, $V_{P}$ 
and $V_{N}$ the respective volumes of the $\mathrm{P}$ and $\mathrm{N}$ chambers, $S$ the piston effective surface and $k$ the polytropic coefficient chosen experimentally. The chambers volumes are computed as follows:

$$
\left\{\begin{array}{l}
V_{P}(y)=V_{0}+S y \\
V_{N}(y)=V_{0}-S y
\end{array}\right.
$$

with $y$ the piston position (defined as zero in central position) and $V_{0}$ the cylinder half volume. The latter includes the cylinder dead volume which ensures that $V_{0}>S\left|y_{\max }\right|$ (where $y_{\max }$ stands for the cylinder's half stroke as defined in Fig. 2 ) and therefore that $V_{P}$ and $V_{N}$ are positive.

\section{B. Mechanical model}

The pneumatic force created by the cylinder can be computed as:

$$
F_{\text {pneu }}=S\left(p_{P}-p_{N}\right)
$$

Thus, the mechanical behavior of the system can be described as:

$$
\left\{\begin{array}{l}
\frac{d v}{d t}=\frac{1}{M}\left[F_{\text {pneu }}-b v-F_{d r y}(v)\right] \\
\frac{d y}{d t}=v
\end{array}\right.
$$

with $M$ the moving mass, $b$ the cylinder and load viscous friction coefficient and $F_{d r y}(v)$ a function of the velocity representing the dry friction phenomena. Any external force $F_{\text {ext }}$ applied on the piston is regarded as an unknown disturbance to be rejected by the control therefore it is not considered in the model for control synthesis.

The dry friction is often modeled by the well-known Tustin model [15]. In this paper, since the control law is meant to be tested in real-time, a simpler approximation is chosen:

$$
F_{d r y}= \begin{cases}F_{s} \frac{v}{v_{L}} & \text { if }|v| \leq v_{L}, \\ F_{s} & \text { if }|v|>v_{L}\end{cases}
$$

where $F_{S}$ is the dry friction absolute value and $v_{L}$ is the velocity limit which separates the progressive friction phase from the constant friction phase.

\section{Servovalve inverse model}

In the previously proposed model (1), the system's two inputs are the servovalves mass flow rates $q_{m_{P}}$ and $q_{m_{N}}$. Considering the supply and exhaust pressures to be constant, the mass flow rate depends on both the control voltage and the pressure of the chamber supplied. Since the actual output of the control law has to be the servovalves control voltages, an inverse model of the servovalves is required.

The steady state flow behavior of the chosen servovalve described in Section II has been thoroughly characterized for many chamber pressure - control voltage couples at a supply pressure of 7 bar. Partial results can be seen in Fig. 3. They show a strongly non-linear behavior: mass flow rate saturations for extreme control voltages and a very important dead zone

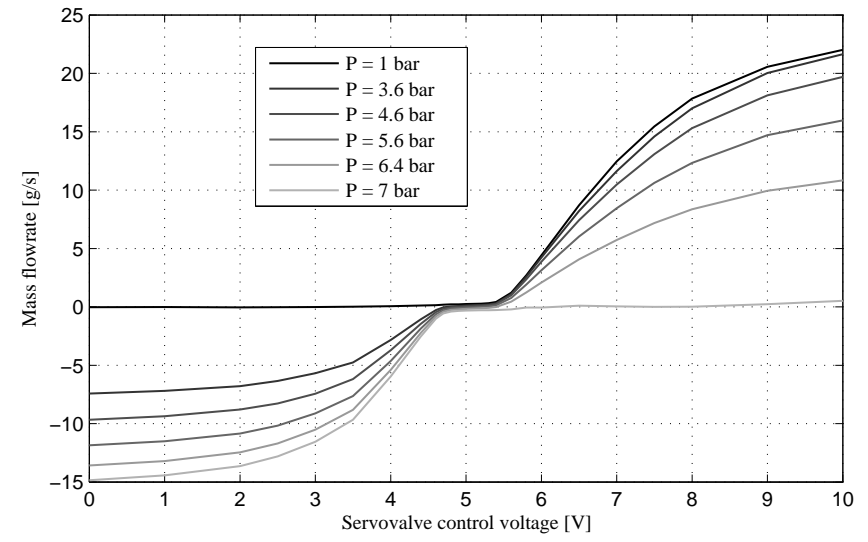

Fig. 3. Partial results of the servovalve experimental characterization

around the central control voltage which is characteristic of a large overlap at the servovalve neutral position.

The servovalve dynamics are neglected since they are supposed to be very fast compared to the pressure dynamics in the cylinder. The three-dimensional experimental table (which includes over 150 entries) is therefore used to directly derive the control voltage. A simple weighted mean of the surrounding values (see Fig. 4) gives a good approximation between the measured values. This experimental inverse model allows

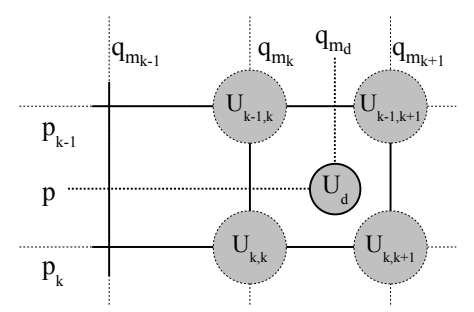

Fig. 4. Computation of the servovalve control voltage $U_{d}$ to generate a desired mass flow rate $q_{m_{d}}$ in a chamber at measured pressure $p$ using the surrounding values of the experimental table

the synthesis of control laws taking the mass flow rates as inputs of the system.

\section{THE A-T TRANSFORMATION}

In the previous section, $q_{m P}$ and $q_{m}$ have been defined as the system inputs. Each one acts on the respective chamber pressure derivative $d p_{P} / d t$ or $d p_{N} / d t$. Choosing the classical state vector $\mathbf{x}=\left[\begin{array}{lllll}y & v & F_{\text {pneu }} & K_{\text {pneu }}\end{array}\right]^{\prime}$, the state equations are the following:

$$
\left\{\begin{array}{l}
\frac{d y}{d t}=v \\
\frac{d v}{d t}=\frac{-b v-F_{d r y}(v)+S\left(p_{P}-p_{N}\right)}{M} \\
\frac{d p_{P}}{d t}=\frac{k r T}{V_{P}}\left(q_{m_{P}}-\frac{S}{r T} p_{P} v\right) \\
\frac{d p_{N}}{d t}=\frac{k r T}{V_{N}}\left(q_{m_{N}}+\frac{S}{r T} p_{N} v\right)
\end{array}\right.
$$


This model, even if it has been widely used to design efficient control strategies in the past decades, shows to flaws:

- it is not in a strict feedback form, which is not ideal for recursive control strategies such as backstepping,

- since pressure control is not the final objective, the inputs $q_{m_{P}}$ and $q_{m_{N}}$ do not control critical ouputs.

For these reasons, merely to simplify the analysis and the control strategies design of the electropneumatic actuators, an alternative choice of inputs, which actually control the critical outputs, is defined. Therefore two virtual mass flow rates $q_{m_{A}}$ and $q_{m T}$ are introduced. They can be derived from the actual mass flow rates by means of this very simple transformation:

$$
\left[\begin{array}{l}
q_{m_{A}} \\
q_{m_{T}}
\end{array}\right]=\Lambda(y)\left[\begin{array}{l}
q_{m_{P}} \\
q_{m_{N}}
\end{array}\right]
$$

with the following transformation matrix:

$$
\begin{aligned}
& \Lambda(y)=V_{0}\left[\begin{array}{cc}
\frac{1}{V_{P}(y)} & -\frac{1}{V_{N}(y)} \\
\frac{1}{V_{P}(y)} & \frac{1}{V_{N}(y)}
\end{array}\right] . \\
& \operatorname{det}(\Lambda(y))=\frac{2 V_{0}}{V_{P}(y) V_{N}(y)} \neq 0 \forall y
\end{aligned}
$$

According to (9) the matrix is invertible for any position of the piston.

As previously stated (4), the pneumatic force generated by the cylinder depends on the pressure difference $\Delta p$ which can be computed as:

$$
\Delta p=p_{P}-p_{N} .
$$

Its derivative can be computed combining equations (1) and (7):

$$
\frac{d \Delta p}{d t}=-k S v\left(\frac{p_{P}}{V_{P}}+\frac{p_{N}}{V_{N}}\right)+\frac{T k r}{V_{0}} q_{m_{A}} .
$$

On the other hand, the average pressure in the cylinder $p_{T}$ has no impact on the pneumatic force, it can be computed as:

$$
p_{T}=\frac{p_{P}+p_{N}}{2} .
$$

Its derivative can be computed combining equations (1) and (7):

$$
\frac{d p_{T}}{d t}=\frac{k S v}{2}\left(\frac{p_{N}}{V_{N}}-\frac{p_{P}}{V_{P}}\right)+\frac{T k r}{2 V_{0}} q_{m T} .
$$

According to equations (11) and (13), $q_{m_{A}}$ only acts on the pressure difference $\Delta p$. Therefore, this virtual input is the active mass flow rate which controls the cylinder pneumatic force. On the other hand, $q_{m T}$ can only induce a symmetrical pressurization, without modifying the pneumatic force and therefore corresponds to the pressurization mass flow rate. This way, two virtual inputs are defined, they actually control two independent behaviors of the electro-pneumatic cylinder: the force generation and the symmetrical pressurization.

This A-T transformation is similar to the d-q Park Transform [16] used in three-phase electric motors control (which involves the calculation of the two current components which respectively generate the flux and the torque).

\section{Alternative state Vector}

The use of two independent servovalves gives the system two degrees of freedom. Therefore, in addition to the position, MIMO control strategies generally [5] propose to choose one of the chambers pressures as a second output. Using the previously proposed transformation (see Section IV), it is now easy to choose an alternative additional output. In this paper, the pneumatic stiffness $\left(K_{\text {pneu }}\right)$ is controlled instead of a chamber pressure. This choice is made because its value is far more meaningful and can be controlled for a specific purpose.

Thus, the first step of control synthesis is the choice of the following state vector: $\mathbf{x}=\left[\begin{array}{lllll}y & v & F_{\text {pneu }} & K_{\text {pneu }}\end{array}\right]^{\prime}$ where [10]:

$$
K_{\text {pneu }}=\left(\frac{p_{P}}{V_{P}(y)}+\frac{p_{N}}{V_{N}(y)}\right) k S^{2} .
$$

Therefore, combining the new state vector with (3), (4), (7), (8), (11), (13) and (14), the model for control synthesis becomes:

$$
\left\{\begin{array}{l}
\frac{d y}{d t}=v \\
\frac{d v}{d t}=\frac{-b v-F_{d r y}(v)+F_{\text {pneu }}}{M} \\
\frac{d F_{\text {pneu }}}{d t}=-K_{\text {pneu }} v+B_{1} q_{m A} \\
\frac{d K_{\text {pneu }}}{d t}=\frac{A_{1} K_{\text {pneu }} y v-A_{2} F_{\text {pneu }} v-B_{2} y q_{m A}+B_{3} q_{m T}}{V_{N} V_{P}}
\end{array}\right.
$$

where:

$$
\begin{aligned}
& A_{1}=2 S^{2}(k+1), \quad A_{2}=S^{2} k(k+1), \\
& B_{1}=S \frac{T k r}{V_{0}}, \quad B_{2}=\frac{S^{3} k^{2} T r}{V_{0}}, \quad B_{3}=S^{2} k^{2} T r .
\end{aligned}
$$

The proposed state equations show a strict feedback form which is particularly adapted for control synthesis, especially when using the backstepping recursive method. Moreover, the derivative of the pneumatic force thus rewritten, clearly shows the two physical phenomena resulting in force generation:

- $-K_{\text {pneu }} v$ the pneumatic stiffness which tends to oppose any movement of the piston,

- $B_{1} q_{m_{A}}$ the active mass flow rate which can be used to control the piston pneumatic force.

It has to be noted that the pneumatic stiffness dynamics depends on both $q_{m_{A}}$ and $q_{m_{T}}$. Still, as it will be shown in Section VI, it has no consequences on the complexity of control synthesis.

\section{BACKSTEPPING CONTROL SYNTHESIS}

Since the system has two degrees of freedom, it can be controlled to simultaneously track two independent trajectories. The first one will be the position, defined by the desired jerk $j_{d}$ and its integrals : the desired acceleration, velocity and position : $a_{d}, v_{d}$ and $y_{d}$. The second one will be the pneumatic stiffness trajectory which is defined by the desired pneumatic stiffness derivative: $d K_{\text {pneu }}^{d} / d t$. 


\section{A. Control law synthesis - position trajectory tracking}

First, the position error is introduced:

$$
z_{1}=y-y_{d} .
$$

Its derivative can be computed as: $\dot{z_{1}}=v-v_{d}$. In accordance with the backstepping methodology [17], $v$ is a virtual input and has to be chosen to cancel and stabilize the error $z_{1}$ :

$$
v=v_{d}-C_{1} z_{1}
$$

with $C_{1}$ a positive constant. To assess the global stability of the subsystem, the following Lyapunov function: $V_{1}=z_{1}^{2} / 2 \geq 0$ is chosen. Its derivative can be computed as:

$$
\dot{V}_{1}=-C_{1} z_{1}^{2} \leq 0 .
$$

Its negativity ensures the stability of the subsystem. In (18), the " $\leq$ " sign is used for the sake of clarity, it has to be noted that $\dot{V}_{1}$ is actually negative except for the desired equilibrium defined by $z_{1}=0$ for which it is canceled. The same applies to the Lyapunov function derivatives $\left(\dot{V}_{2}, \dot{V}_{3}\right.$ and $\left.\dot{V}_{4}\right)$ introduced later).

The next error variable $z_{2}$ is defined as:

$$
z_{2}=v-v_{d}+C_{1} z_{1}
$$

It leads to:

$$
\dot{z}_{1}=z_{2}-C_{1} z_{1}
$$

and:

$$
\dot{z}_{2}=\frac{F_{\text {pneu }}-b v-F_{d r y}(v)}{M}-a_{d}+C_{1} z_{2}-C_{1}^{2} z_{1} .
$$

A new Lyapunov candidate function $V_{2}=V_{1}+z_{2}^{2} / 2 \geq 0$ and the following pneumatic effort control are defined:

$$
\begin{aligned}
F_{\text {pneu }}^{d}= & M\left(a_{d}-z_{2}\left(C_{1}+C_{2}\right)+z_{1}\left(C_{1}^{2}-1\right)\right) \\
& +b v+F_{d r y}(v)
\end{aligned}
$$

with $C_{2}$ a positive constant. If $F_{\text {pneu }}=F_{\text {pneu }}^{d}$ is ensured, then the error derivative can be computed as $\dot{z}_{2}=-z_{1}-C_{2} z_{2}$ which eventually leads to $\dot{V}_{2}=-C_{1} z_{1}^{2}-C_{2} z_{2}^{2}$. The negativity of this derivative ensures the subsystem's global stability. The next error variable $z_{3}$ is then introduced:

$$
z_{3}=F_{\text {pneu }}-F_{\text {pneu }}^{d} .
$$

It leads to:

$$
\dot{z_{2}}=\frac{z_{3}}{M}-z_{1}-C_{2} z_{2}
$$

and:

$$
\begin{aligned}
\dot{z_{3}}= & B_{1} q_{m_{A}}-K_{\text {pпеи }} v-M j_{d} \\
& -\frac{b\left(F_{\text {pneu }}-b v-F_{d r y}(v)\right)}{M} \\
& +M\left(C_{1}^{3}-2 C_{1}-C_{2}\right) z_{1}+\left(C_{1}+C_{2}\right) z_{3} \\
& +M\left(1-C_{1}^{2}-C_{2}^{2}-C_{1} C_{2}\right) z_{2} .
\end{aligned}
$$

For practical reasons, it is considered that $d F_{d r y} / d t=0$ which is not valid for very small velocities. To avoid this theoretical issue, it is often proposed to model the dry friction phenomenon using the continuous arctangent function [7]. It is a computationally-expensive solution which does not demonstrate any practical advantage and has therefore not been used in this work.

In order to cancel any pneumatic force steady state error which might be introduced by an external force, the pneumatic force integral error is also defined:

$$
z_{3 i}=\int z_{3} d t .
$$

A third Lyapunov function can then be defined as:

$$
V_{3}=V_{2}+\frac{z_{3}^{2}}{2}+K_{i} \frac{z_{3 i}^{2}}{2} \text {. }
$$

With $K_{i}$ a positive constant. If the following active mass flow rate control is chosen:

$$
q_{m_{A}}=f_{0}+f_{1} z_{1}+f_{2} z_{2}+f_{3} z_{3}+f_{4} z_{3 i}
$$

where:

$$
\begin{aligned}
f_{0} & =\frac{M^{2} j_{d}+M K_{\text {pпеи }} v-v b^{2}-b F_{\text {dry }}+F_{\text {pпеи }} b}{M B_{1}}, \\
f_{1} & =-\frac{M\left(C_{1}^{3}-2 C_{1}-C_{2}\right)}{B_{1}}, \\
f_{2} & =\frac{M^{2}\left(C_{1}^{2}+C_{1} C_{2}+C_{2}^{2}-1\right)-1}{M B_{1}}, \\
f_{3} & =-\frac{C_{1}+C_{2}+C_{3}}{B_{1}}, \\
f_{4} & =-\frac{K_{i}}{B_{1}}
\end{aligned}
$$

with $C_{3}$ a positive constant, then $\dot{V}_{3}=-C_{1} z_{1}^{2}-C_{2} z_{2}^{2}-$ $C_{3} z_{3}^{2} \leq 0$. According to the Lasalle Yoshizawa theorem [18], the integral error $z_{3 i}$ will then be bounded and the three errors $z_{1}, z_{2}$ and $z_{3}$ will converge to zero. The position, velocity and pneumatic force errors will therefore asymptoticly converge to zero.

In this first part of the control synthesis, the virtual mass flow-rate $q_{m_{A}}$ which ensures that the cylinder will follow the desired position trajectory has been computed. At this point, no choice has been made regarding the $q_{m_{T}}$ control.

\section{B. Pneumatic stiffness trajectory tracking}

A new error variable $z_{4}$ can be defined as: $z_{4}=K_{\text {pneu }}-$ $K_{\text {pneu }}^{d}$. Its derivative can be computed as follows:

$$
\begin{aligned}
\dot{z}_{4} & =\frac{A_{1} K_{\text {pneu }} v y-A_{2} \cdot F_{\text {pneu }} v-y B_{2} q_{m_{A}}+B_{3} q_{m T}}{V_{N} V_{P}} \\
& -\frac{d K_{\text {pneu }}^{d}}{d t} .
\end{aligned}
$$

A last Lyapunov function is defined as: $V_{4}=V_{3}+z_{4}^{2} / 2 \geq$ 0 and the following pressurization mass flow rate control is chosen:

$$
\begin{aligned}
q_{m_{T}} & =\frac{1}{B_{3}}\left[A_{2} F_{\text {pneu }} v+V_{N} V_{P}\left(\frac{d K_{\text {pneu }}^{d}}{d t}-C_{4} z_{4}\right)\right. \\
& \left.-A_{1} K_{\text {pneu }} v y+B_{2} y q_{m_{A}}\right]
\end{aligned}
$$


with $C_{4}$ a positive constant. It leads to: $\dot{V}_{4}=-C_{1} . z_{1}^{2}-C_{2} . z_{2}^{2}-$ $C_{3} . z_{3}^{2}-C_{4} . z_{4}^{2} \leq 0$ which means that the cylinder pneumatic stiffness will track the trajectory defined by $d K_{p n e u}^{d} / d t$ and its integral $K_{\text {pneu }}^{d}$.

The pressurization mass flow rate $q_{m T}$ depends on the value of $q_{m_{A}}$ but since the latter has already been computed in the position tracking control law, $q_{m_{T}}$ can be derived explicitly.

Once the two virtual mass flow rates $q_{m_{A}}$ and $q_{m_{T}}$ are computed, the actual mass flow rate controls can be calculated using the inverse A-T transformation defined in Section IV:

$$
\left[\begin{array}{l}
q_{m_{P}} \\
q_{m_{N}}
\end{array}\right]=\Lambda^{-1}(y)\left[\begin{array}{l}
q_{m_{A}} \\
q_{m_{T}}
\end{array}\right] .
$$

The whole control law (Fig. 5) requires the measurement of both pressures $p_{P}$ and $p_{N}$ (used to compute $F_{\text {pneu }}$ and $K_{\text {pneu }}$ ) as well as the piston position $y$ and velocity $v$.

\section{Closed-LoOP BehaVIOR TUNING STRATEGY}

The tuning of a non-linear control strategy is always a complex task since the control parameters seldom show an obvious physical meaning. It is usually done by trial and error which is time consuming, complex and inaccurate, often preventing the algorithm from being used in industrial applications. In this section is proposed a simple yet very efficient way to choose the proposed nonlinear control law parameters by defining the cylinder behavior using linear concepts.

\section{A. Pneumatic stiffness and closed-loop stiffness}

In this paper two different concepts referred to as "stiffness" are studied. The first one is the pneumatic stiffness $K_{\text {pneu }}$ defined in (14). As previously stated, it depends on the piston position and the pressures in both chambers. It represents the cylinder natural tendency to counteract an external force applied on the piston. When position control is imposed to the electro-pneumatic system, the pneumatic stiffness can be considered as the system's "open-loop stiffness", which influence is compensated by the control law as shown in (28) and (29). The "open-loop" term can be misleading since the pneumatic stiffness is also a controlled state variable but it underlines the fact that, in the absence of a position control loop, it is the only stiffness phenomenon resisting the piston displacement.

On the other hand, when the piston position is controlled, the stiffness which is actually imposed by the actuator is the "closed-loop stiffness" $K_{c l}$. Unline $K_{\text {pneu }}$, it is not an intrinsic physical phenomenon but a parameter of the position control law and therefore is the actual expected behavior of the system when submitted to an external force.

The closed-loop stiffness is defined as the actuating system response from a displacement from its desired position:

$$
K_{c l}=-\frac{d F}{d z_{1}}
$$

where $F$ stands for the total force generated by the electropneumatic actuator (that is the pneumatic force minus the friction losses) and $z_{1}$ stands for the previously defined position error.

\section{B. Tuning of the closed-loop stiffness}

In order to do define a tuning strategy, the pneumatic force error $z_{3}$ defined in equation (23) is assumed to be successfully canceled by the active mass flow rate $q_{m_{A}}$ computed in equations (28) and (29). This is obviously an approximation and it is done for tuning purposes only. Thus, the following hypothesis is adopted: $F_{\text {pneu }}=F_{\text {pneu }}^{d}$. Therefore $F$ the sum of the forces applied on the load by the actuator can be computed as:

$$
\begin{aligned}
F & =F_{\text {pneu }}^{d}-b v-F_{d r y}(v) \\
& =M\left(a_{d}-z_{2}\left(C_{1}+C_{2}\right)+z_{1}\left(C_{1}^{2}-1\right)\right) .
\end{aligned}
$$

Therefore, according to (33) and (34), the closed-loop stiffness can be computed as:

$$
K_{c l}=-M \frac{d\left(a_{d}-z_{2}\left(C_{1}+C_{2}\right)+z_{1}\left(C_{1}^{2}-1\right)\right)}{d z_{1}}
$$

and, since $z_{2}=v-v_{d}+C_{1} z_{1}, d a_{d} / d z_{1}=0$ and $d(v-$ $\left.v_{d}\right) / d z_{1}=0$ :

$$
\begin{aligned}
K_{c l} & =-M \frac{d\left(-C_{1} z_{1}\left(C_{1}+C_{2}\right)+z_{1}\left(C_{1}^{2}-1\right)\right)}{d z_{1}} \\
& =M\left(C_{1} C_{2}+1\right) .
\end{aligned}
$$

\section{Definition of the closed-loop damping}

Likewise, the closed-loop damping can be defined as the actuating system response to a velocity error:

$$
B_{c l}=-\frac{d F}{d \bar{v}}
$$

with $\bar{v}=v-v_{d}$, the velocity error. From Eq.(34) it comes:

$$
B_{c l}=-M \frac{d\left(a_{d}-z_{2}\left(C_{1}+C_{2}\right)+z_{1}\left(C_{1}^{2}-1\right)\right)}{d \bar{v}} .
$$

Since $z_{2}=\bar{v}+C_{1} z_{1}, d z_{2} / d \bar{v}=1$ which leads to:

$$
B_{c l}=M\left(C_{1}+C_{2}\right) .
$$

\section{Computation of the control law parameters}

In order to ensure that the actuation system will respect the closed-loop stiffness $K_{c l}$ and closed-loop damping $B_{c l}$, the corresponding $C_{1}$ and $C_{2}$ parameters have to be computed accordingly. From (36) the following can be derived:

$$
C_{2}=\frac{K_{c l}-M}{C_{1} M} .
$$

The global stability of the system requires $C_{1}>0$ and $C_{2}>0$. This provides a first condition: $K_{c l}>M$. From (39) and (40), the following equation can be derived:

$$
M C_{1}^{2}-B_{c l} C_{1}+K_{c l}-M=0
$$

As the solutions of this second order equation have to be real and positive, a second condition can be defined: $B_{c l} \geq$ $2 \sqrt{M\left(K_{c l}-M\right)}$. 
Finally, the control parameters can be computed and there is only one practical solution as $C_{1}$ and $C_{2}$ values are interchangeable:

$$
\left\{\begin{array}{c}
C_{1}=\frac{B_{c l}+\sqrt{B_{c l}^{2}-4 M\left(K_{c l}-M\right)}}{2 M} \\
C_{2}=\frac{B_{c l}-\sqrt{B_{c l}^{2}-4 M\left(K_{c l}-M\right)}}{2 M}
\end{array} .\right.
$$

The two conditions:

$$
\left\{\begin{array}{l}
B_{c l} \geq 2 \sqrt{M\left(K_{c l}-M\right)} \\
K_{c l}>M
\end{array}\right.
$$

ensure the global stability of the system.

\section{E. Closed-loop regulation behavior}

According to (22), (36) and (39), the pneumatic force control provided by the backstepping based algorithm can be expressed as follows:

$$
F_{\text {pneu }}^{d}=-K_{c l} z_{1}-B_{c l} \bar{v}+M a_{d}+b v+F_{d r y}(v) .
$$

If the previously proposed approximation $F_{\text {pneu }}=F_{\text {pneu }}^{d}$ is made, the closed loop behavior of the cylinder in regulation when submitted to an unknown external force $F_{\text {ext }}$ can be described as:

$$
M \frac{d v}{d t}=F=F_{\text {pneu }}^{d}-b v-F_{d r y}(v)-F_{\text {ext }} .
$$

Hence, according to (44):

$$
M \frac{d v}{d t}=M a_{d}-K_{c l} z_{1}-B_{c l} \bar{v}-F_{e x t} .
$$

And:

$$
M \bar{a}=-K_{c l} z_{1}-B_{c l} \bar{v}-F_{e x t}
$$

where $\bar{a}=\dot{v}-a_{d}$. Finally, since $\bar{v}=\dot{z}_{1}$ and $\bar{a}=\dot{\bar{v}}$ :

$$
M \ddot{z}_{1}=-K_{c l} z_{1}-B_{c l} \dot{z}_{1}-F_{\text {ext }} .
$$

It has to be noted that this study neglects the error $z_{3}$ defined by (23) and therefore has absolutely no value as a stability proof but merely provides information about the algorithm tuning. In accordance with the approximation (45), the piston response to an external disturbance in the Laplace domain can be expressed as follows:

$$
H_{\text {reg }}(s)=\frac{z_{1}(s)}{F_{\text {ext }}(s)}=-\frac{1}{M s^{2}+B_{c l} s+K_{c l}} .
$$

This transfer function corresponds to a classical spring-mass system with friction. The static gain $G$, natural frequency $\omega_{n}$ and damping ratio $\xi$ of the second order transfer function are then computed:

$$
G=-\frac{1}{K_{c l}}, \quad \omega_{n}=\sqrt{\frac{K_{c l}}{M}} \quad \text { and } \quad \xi=\frac{B_{c l}}{2 \sqrt{K_{c l} M}} .
$$

Which leads to the following tuning rules:

- the condition for a non-oscillatory response of the piston to an external force is: $B_{c l} \geq 2 \sqrt{K_{c l} M}$
- the steady-state error can be computed as $\Delta_{y}=$ $-F_{e x t} / K_{c l}$ therefore increasing the system closed-loop stiffness will reduce the static error when the system is submitted to an external disturbance force

- the damping ratio is proportional to $B_{c l}$. This implies that, in the non-oscillatory response case, the convergence time will be increased by a high closed-loop damping. In other words, it expresses the control ability to slow down the piston without altering the steady-state position.

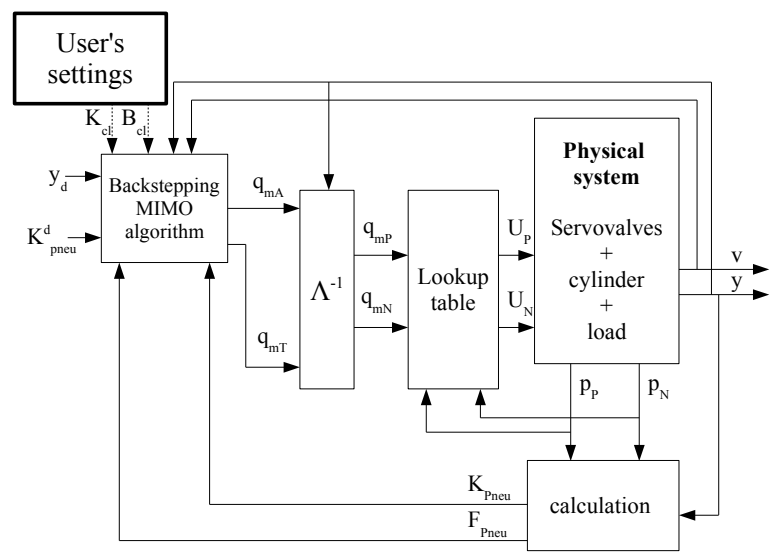

Fig. 5. Principle of the control strategy

\section{F. Remaining control parameters}

In order to better understand the $C_{3}, K_{i}$ and $C_{4}$ constants influence over the system response, the following derivatives have to be computed:

$$
\begin{aligned}
\frac{d q_{m_{A}}}{d C_{3}} & =-\frac{z_{3}}{B_{1}} \\
\frac{d q_{m_{A}}}{d K_{i}} & =-\frac{\int z_{3} d t}{B_{1}} \\
\frac{d q_{m_{T}}}{d C_{4}} & =-z_{4} \frac{V_{N} V_{P}}{B_{3}}
\end{aligned}
$$

(51) shows that $C_{3}, K_{i}$ and $C_{4}$ respectively set the feedback gain of the pneumatic force error, the pneumatic force integral error and the pneumatic stiffness error. Increasing these values can enhance the pneumatic force and stiffness responses up to a certain point but will also increase the servovalves work and, possibly, the gas consumption. A trade-off between the response quality and the energy consumption and actuators aging has to be defined depending on the expected performances.

It has to be noted that, since the tuning strategy proposed in Section VII is based on the assumption that the pneumatic force error is negligible, a good pneumatic force precision is required and therefore reasonably high values of the parameters $C_{3}$ and $K_{i}$ have to be set. The pneumatic stiffness precision is generally less critical and therefore the value of $C_{4}$ can be chosen smaller.

\section{ABOUT STIFFNESSES}

A common misconception regarding electro-pneumatic systems performances is that they have a low stiffness. This 
is true in an open-loop configuration, since only the pneumatic stiffness opposes the piston movement. However, when controlled to track a position trajectory, an electro-pneumatic cylinder closed-loop stiffness can be chosen at any given value, smaller or larger than the open-loop stiffness. Nevertheless, the simplicity of the tuning strategy can be misleading and it is important to keep in mind that there are physical limitations to this closed-loop tuning:

- the pneumatic force is limited by the supply pressure and the piston surface. When submitted to an external force which exceeds the maximum pneumatic force, the actual closed-loop stiffness will inevitably collapse,

- the pneumatic force dynamics is limited by the servovalves maximum mass flow rate (which depends on the supply pressure and the servovalve maximum flow area). If mass flow rate saturation occurs, the electro-pneumatic system cannot control the pneumatic force fast enough to meet the closed-loop tuning,

- finally the servovalves dynamics, which are neglected in the control synthesis model, will also impact the closed-loop tuning: when a large displacement of the servovalve's spool is needed for a large variation of the mass flow rate, the non-modeled response time will decrease the tuning precision.

Therefore a thorough sizing task has to be conducted regarding the cylinder and servovalves characteristics for a given set of technical specifications (moving mass, maximum external force, required closed-loop stiffness...) in order to avoid saturations, reduce servovalves response delays and therefore ensure the good precision of the closed-loop tuning.

Finally, even if the pneumatic stiffness influence over the piston displacement is compensated by the position control law, it can be interesting, when possible, to specify a pneumatic stiffness trajectory consistent with the chosen closedloop stiffness. The closer the pneumatic stiffness will be to the closed-loop stiffness, the less the servovalve will have to act, reducing the risk of saturations mentioned before and enhancing the tuning precision. Virtually, if the closed-loop stiffness were to be chosen exactly equal to the pneumatic stiffness, the pneumatic cylinder would naturally display the desired closed-loop stiffness without requiring any action from the servovalves. This is an important remark for it underlines the hybrid nature of this VSA technology which is both passive and active (see Section I).

\section{TEST BENCH OVERVIEW}

In order to assess the efficiency of the proposed control strategy and all its future applications, a whole new test bench has been developed. Classical linear test bench designs generally include a variable load which inertia [19] or stiffness [20] can be tuned to evaluate the control robustness towards parameters uncertainties. The most common limitation of those solutions lies in the lack of external disturbances generation. [21] proposes to use a second antagonistic pneumatic actuator but the latter is not really suited for swift step force generation. Among the actuators candidates, electric solutions are preferred to hydraulic ones because, in one hand, their range of efforts are more compatible with a pneumatic actuator and, in the other hand, they are easier to supply and control. EMA can be an attractive solution because they are inexpensive and can generally offer a high continuous effort but only a linear motor can deliver the very high dynamic needed to generate disturbances as swift steps or high frequency forces.

Therefore, the chosen actuator is a linear motor ironcore TB30N model manufactured by Tecmotion. Its main characteristics are summarized in table II. The TB30N is driven by a CDD34017 inverter provided by Lust which carries out force control.

TABLE II

TB30N LINEAR MOTOR CHARACTERISTICS

\begin{tabular}{lll}
\hline \hline Quantity & Value & \\
\hline Maximum continuous force & 1900 & $\mathrm{~N}$ \\
Peak force & 4500 & $\mathrm{~N}$ \\
Maximum speed & 2.5 & $\mathrm{~m} / \mathrm{s}$ \\
Electric time constant & 8 & $\mathrm{~ms}$ \\
\hline \hline
\end{tabular}

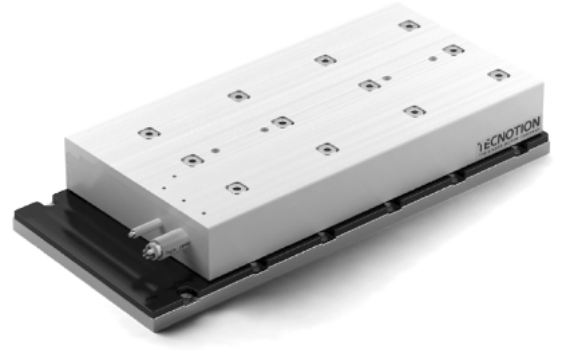

Fig. 6. TB30N linear motor

A cRIO-9022 real time controller from National Instruments is used for sensors and actuators interfacing and the rapid prototyping of the control algorithms. The pressure dynamics in the cylinder are relatively slow, with a response time of roughly $100 \mathrm{~ms}$ and the servovalve MPYE can be considered as about 10 times faster. Therefore, choosing a sampling frequency of $500 \mathrm{~Hz}$ is fast enough compared to the actuators dynamics.

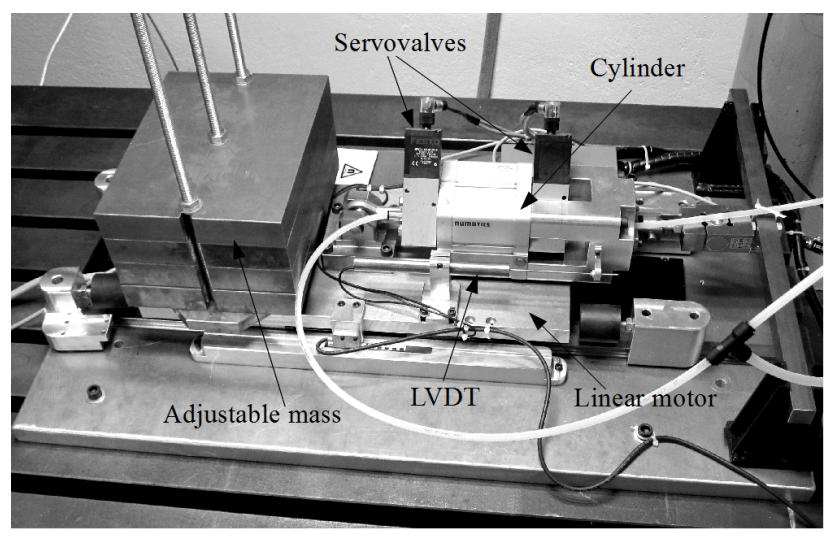

Fig. 7. View of the complete test bench 


\section{EXPERIMENTAL RESULTS}

In order to assess the validity of the proposed tuning strategy, various tests have been conducted using the previously presented test bench. Unless otherwise specified, the pneumatic stiffness trajectory is chosen constant and $K_{\text {pneu }}^{d}=$ $3 \times 10^{5} \mathrm{~N} / \mathrm{m}$. The electro-pneumatic cylinder drives a $125 \mathrm{~kg}$ mass. After each test, the experimental closed-loop stiffness is derived using the steady state error $\Delta_{y}$ :

$$
K_{c l m}=\frac{F_{e x t}}{\Delta_{y}}=\frac{F_{e x t}}{\left|y-y_{d}\right|}
$$

and the closed-loop stiffness relative error is defined as:

$$
\Delta K_{c l}=\frac{K_{c l}-K_{c l m}}{K_{c l}} .
$$

Since the main objective of the control strategy is not to minimize the position error but to specify a closed-loop behavior, the $\Delta K_{c l}$ is the actual criterion to assess the algorithm efficiency.

\section{A. Response to force steps for a varying closed-loop stiffness}

In this first test, the piston is controlled to stay still in central position. Swift external force steps of $500 \mathrm{~N}$ are applied on the piston by the linear motor and the closed-loop tuning $K_{c l}$ is changed gradually in real time from $1 \times 10^{5} \mathrm{~N} / \mathrm{m}$ up to $15 \times 10^{5} \mathrm{~N} / \mathrm{m}$. $B_{c l}$ is kept minimal under the (43) criterion. The resulting piston displacement can be seen on Fig. 8 and Table III. The relative error of the closed-loop stiffness stays below $10 \%$.
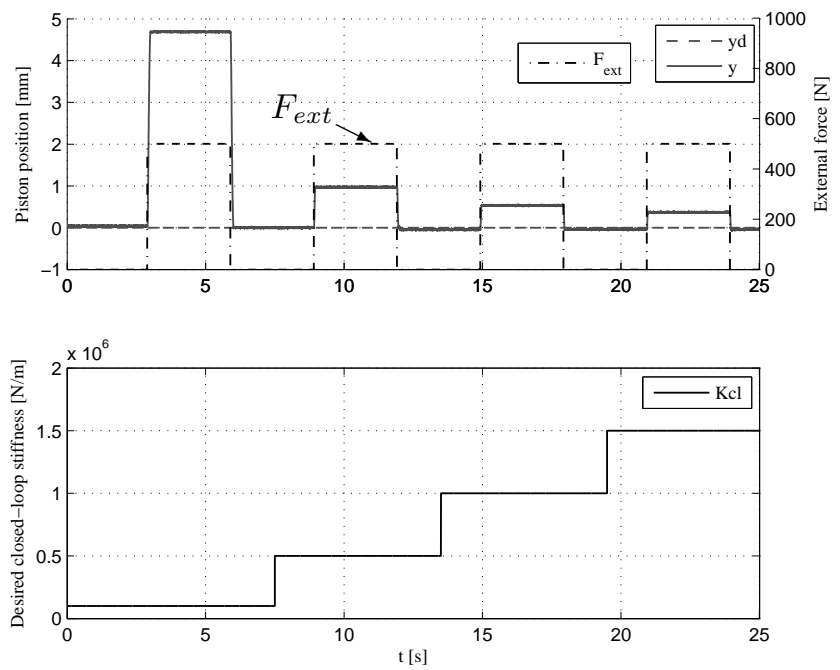

Fig. 8. Position response of the piston to external force steps for a varying closed-loop stiffness tuning [test 1]

TABLE III

Results of TEST 1: $F_{\text {ext }}=500 \mathrm{~N}$, VARIABLE $K_{c l}$

\begin{tabular}{lllll}
\hline \hline$K_{c l}[\mathrm{~N} / \mathrm{m}]$ & $1 \times 10^{5}$ & $5 \times 10^{5}$ & $10 \times 10^{5}$ & $15 \times 10^{5}$ \\
\hline$\Delta_{y}[\mathrm{~mm}]$ & 4.701 & 0.989 & 0.519 & 0.353 \\
\hline$K_{c l m}[\mathrm{~N} / \mathrm{m}]$ & $1.06 \times 10^{5}$ & $5.06 \times 10^{5}$ & $9.63 \times 10^{5}$ & $14.16 \times 10^{5}$ \\
\hline$\Delta K_{c l}[\%]$ & -6.36 & -1.11 & 3.66 & 5.57 \\
\hline \hline
\end{tabular}

\section{B. Response to varying force steps}

The second test is similar except that the closed-loop stiffness is chosen constant at $K_{c l}=5 \times 10^{5} \mathrm{~N} / \mathrm{m}$ while the external force varies from $500 \mathrm{~N}$ up to $1500 \mathrm{~N}$ (see Fig.9).

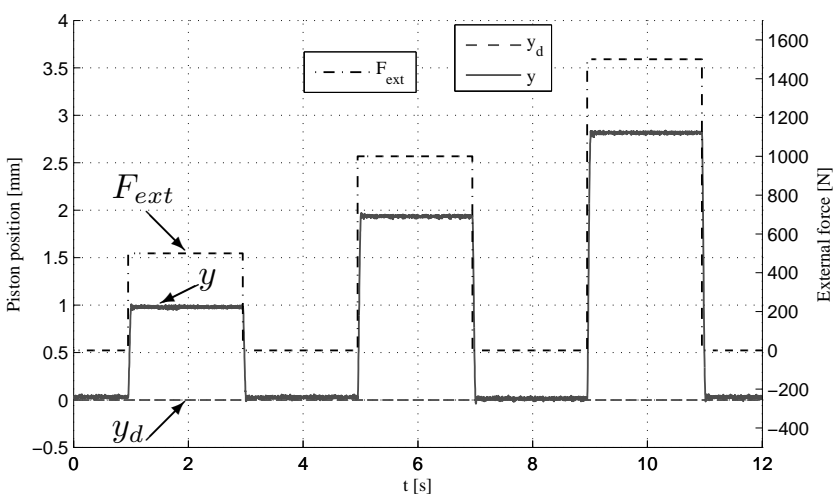

Fig. 9. Position response of the piston to force steps varying from $500 \mathrm{~N}$ to $1500 \mathrm{~N}$ for $K_{c l}=5 \times 10^{5} \mathrm{~N} / \mathrm{m}$ [test 2]

TABLE IV

RESUlts OF TEST 2: $K_{c l}=5 \times 10^{5}$ N/M, VARIABLE $F_{e x t}$

\begin{tabular}{llll}
\hline \hline$F_{e x t}[\mathrm{~N}]$ & 500 & 1000 & 1500 \\
\hline$K_{c l m}[\mathrm{~N} / \mathrm{m}]$ & $5.03 \times 10^{5}$ & $5.12 \times 10^{5}$ & $5.29 \times 10^{5}$ \\
\hline$\Delta K_{c l}[\%]$ & -0.60 & -2.46 & -5.86 \\
\hline \hline
\end{tabular}

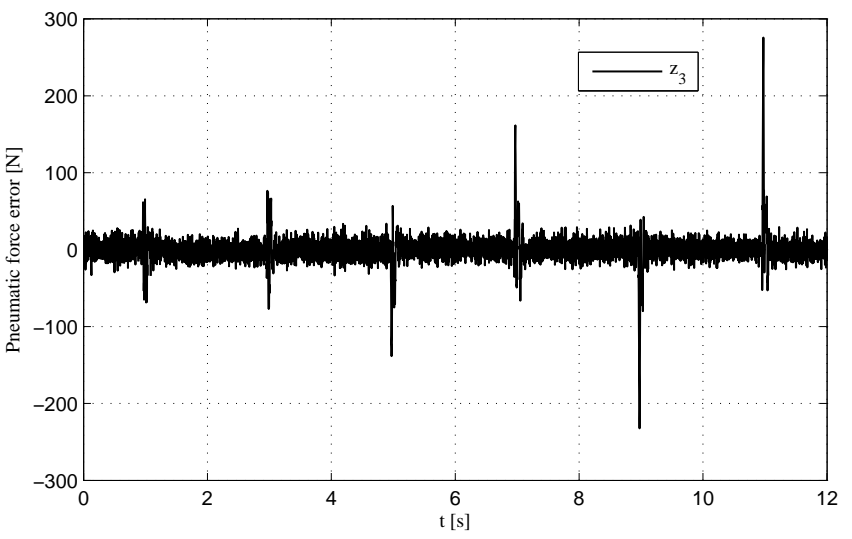

Fig. 10. Pneumatic force error $z_{3}$ when submitted to force steps varying from $500 \mathrm{~N}$ to $1500 \mathrm{~N}$ for $K_{c l}=5 \times 10^{5} \mathrm{~N} / \mathrm{m}$ [test 2]

Table IV shows that the closed-loop stiffness is correctly tuned for any value of the disturbance even if precision slightly decreases with the external force magnitude.

Fig. 10 shows $z_{3}$, defined by (23), the pneumatic force error. The transient error is limited since its value never exceeds $20 \%$ of the external force applied. Moreover, as a result of the integral feedback defined in (26) there is no static error. Therefore, the assumption $z_{3}=0$ made in section VII-B to define the tuning strategy is reasonable. This explains the good tuning precision summarized in table IV. 


\section{Varying closed-loop damping}

In the third test, the closed-loop stiffness is constant at $10^{5}$ $\mathrm{N} / \mathrm{m}$ while the closed-loop damping varies from $6.8 \times 10^{3}$ $\mathrm{N} / \mathrm{m} / \mathrm{s}$ up to $2.4 \times 10^{4} \mathrm{~N} / \mathrm{m} / \mathrm{s}$. For the sake of readability, results have been superimposed.

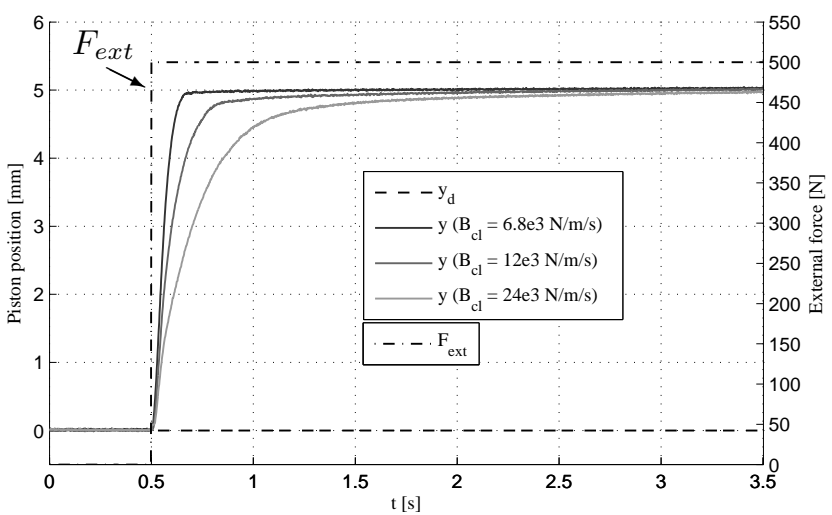

Fig. 11. Position response of the piston to external force steps for three different closed-loop damping tunings [test 3]

Fig.11 clearly demonstrates that the steady state error is unchanged by the closed-loop damping variation and that the latter can be used to set the dynamics of the piston response when submitted to an external force.

\section{Response to force steps for a varying pneumatic stiffness}

In this test, the closed-loop stiffness and damping are constants $\left(K_{c l}=3.5 \times 10^{5} \mathrm{~N} / \mathrm{m}\right.$ and $\left.B_{c l}=1.5 \times 10^{4} \mathrm{~N} / \mathrm{m} / \mathrm{s}\right)$. The pneumatic stiffness varies gradually over the test from $1.5 \times 10^{5} \mathrm{~N} / \mathrm{m}$ up to $3.5 \times 10^{5} \mathrm{~N} / \mathrm{m}$. Non represented external force steps of $500 \mathrm{~N}$ are applied on the piston every five seconds. Figures 12 shows the pneumatic stiffness trajectory tracking as well as the piston displacement resulting from the successive external force disturbances. In figure 13, the active mass flow rates $q_{m A}$ provided by the servovalves at each external force rising edge (at instants $t=\{2.5,12.5,22.5\}$ s) are compared. Results are summarized in table V.

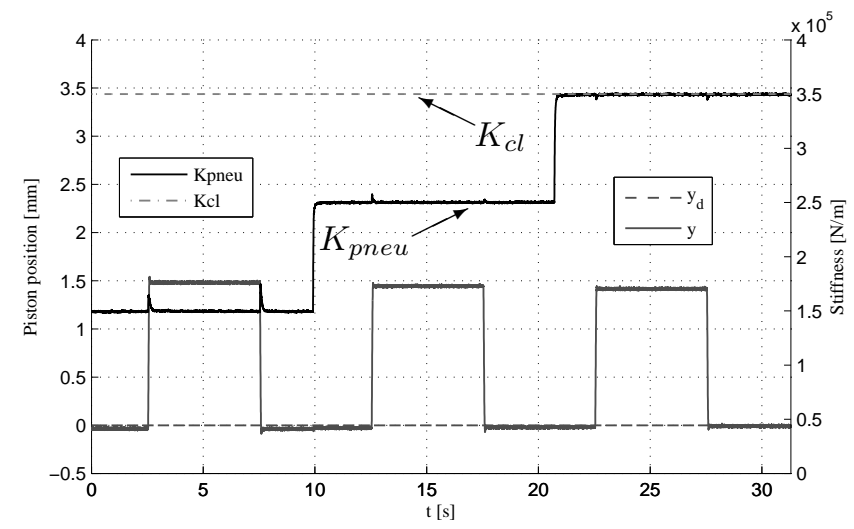

Fig. 12. Position response of the piston to external force steps for a varying pneumatic stiffness [test 4]

The results give the following informations:

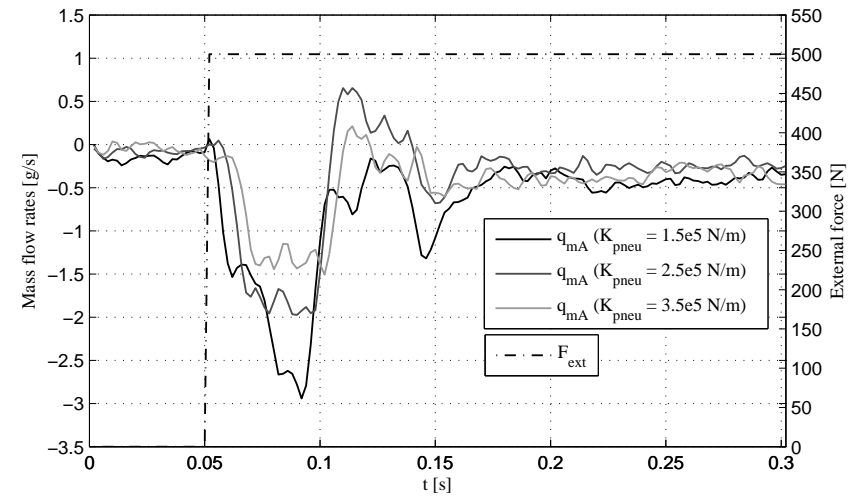

Fig. 13. Active mass flow rates provided by the servovalves at each rising edge of the external force for three different values of the pneumatic stiffness [test 4]

TABLE V

Results of TEST 4: $K_{c l}=3.5 \times 10^{5} \mathrm{~N} / \mathrm{M}, F_{\text {ext }}=500 \mathrm{~N}$

\begin{tabular}{llll}
\hline \hline$K_{\text {pneu }}[\mathrm{N} / \mathrm{m}]$ & $1.5 \times 10^{5}$ & $3 \times 10^{5}$ & $4.5 \times 10^{5}$ \\
\hline$K_{c l_{m}}[\mathrm{~N} / \mathrm{m}]$ & $3.35 \times 10^{5}$ & $3.45 \times 10^{5}$ & $3.52 \times 10^{5}$ \\
\hline$\Delta K_{c l}[\%]$ & 4.3 & 1.4 & -0.6 \\
\hline$\left|q_{m_{A}}\right| \max [\mathrm{g} / \mathrm{s}]$ & 2.94 & 1.97 & 1.51 \\
\hline \hline
\end{tabular}

- the pneumatic stiffness successfully tracks the trajectory (Fig. 12). Variations due to piston displacements are very small,

- the closed-loop behavior does not depend on the pneumatic stiffness, therefore the latter is successfully compensated by the control law and the closed-loop stiffness tuning is respected regardless of the pneumatic stiffness,

- however, setting the pneumatic stiffness close to the closed-loop stiffness enhances the latter's precision,

- the active mass flow rate provided by the servovalves is significantly reduced (Fig. 13) when the pneumatic stiffness is set closer to the desired closed-loop stiffness. This confirms the previously stated hypothesis that the servovalves action is reduced when the open loop stiffness is close to the closed-loop stiffness which will result in energy consumption reduction.

\section{E. Closed-loop stiffness and trajectory tracking}

In the fifth test, a $3 \mathrm{~Hz}$ sinusoidal position trajectory is imposed to the actuator. The closed-loop stiffness is set at a value of $5 \times 10^{5} \mathrm{~N} / \mathrm{m}$ and a $1000 \mathrm{~N}$ force is applied on the piston.

It can be seen on Fig.14 that the position trajectory is precisely tracked when no disturbance is applied. When the piston is submitted to an external force of $1000 \mathrm{~N}$ a permanent error or $2 \mathrm{~mm}$ appears (see Fig.15) which is consistent with the tuning. Therefore, the closed-loop stiffness tuning is also precisely respected when the piston is in movement.

\section{F. Range and precision of the closed-loop stiffness}

Finally, the first test (see Section X-A) has been conducted for over 40 values of the desired closed-loop stiffness $K_{c l}$ 


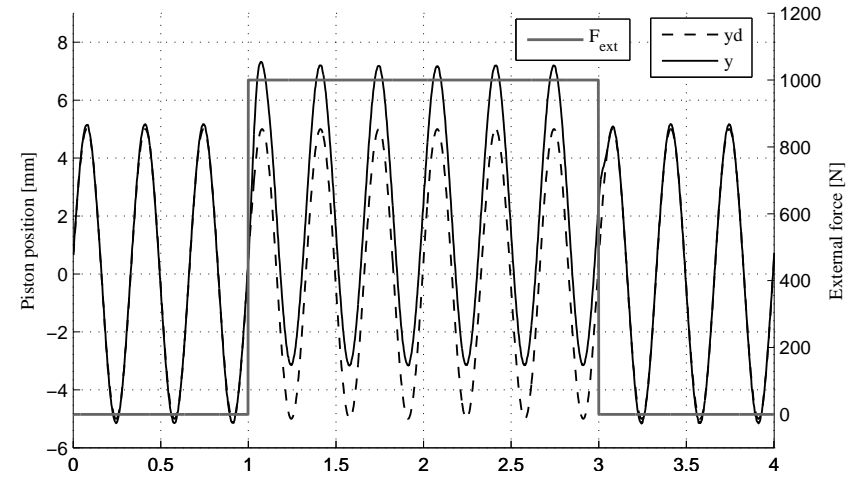

Fig. 14. Position response of the piston to an external force while tracking a sinusoidal trajectory [test 5]

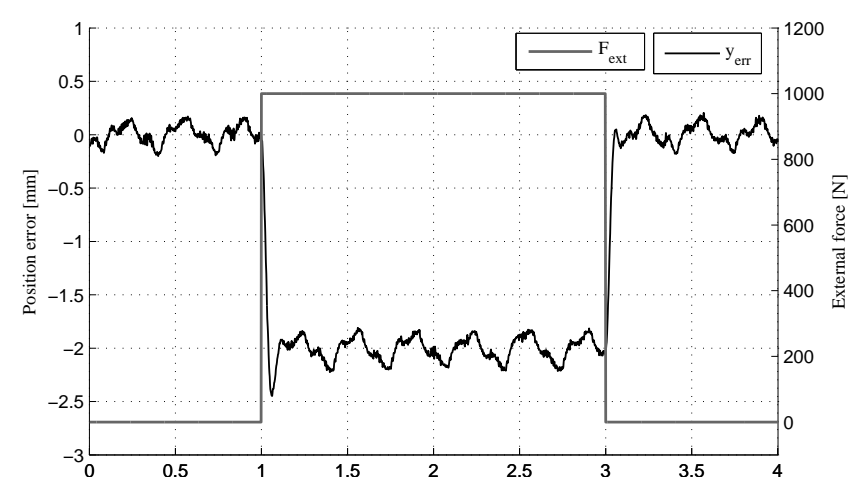

Fig. 15. Position error while tracking a sinusoidal trajectory [test 5]

varying from $3 \times 10^{4} \mathrm{~N} / \mathrm{m}$ to $3 \times 10^{6} \mathrm{~N} / \mathrm{m}$ with the closedloop damping kept to its minimal value.
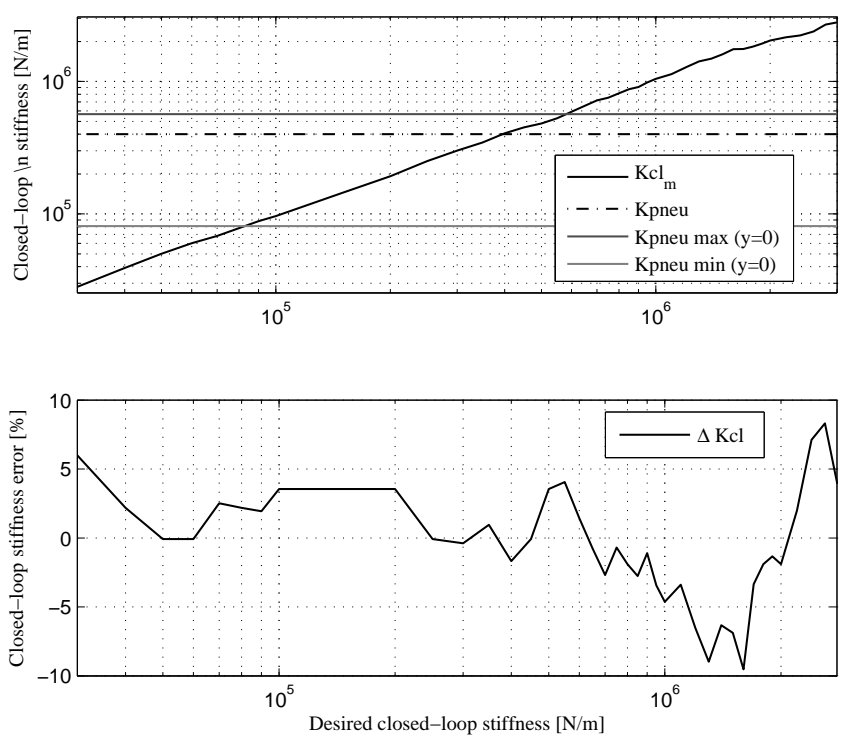

Fig. 16. Stiffness tuning range and precision.

Results show that the closed-loop stiffness can be set with a relative error below $10 \%$ between minimal and maximal values spaced by a factor of 100 (see Fig. 16). Such a range cannot be achieved using solely the pneumatic stiffness (maximal and minimal values of the pneumatic stiffness when the piston is in central position are provided for comparison) and this result clearly underlines the contribution of the proposed algorithm.

\section{CONCLUSION}

In this study, using two virtual inputs $q_{m_{A}}$ and $q_{m_{T}}$ derived from the physical inputs $q_{m P}$ and $q_{m N}$ and the piston position $y$ using the A-T transformation, an alternative state model is obtained. This makes possible the design of a control law which allows the precise tuning of the closed-loop behavior of an electro-pneumatic cylinder has been presented. Experimental results have demonstrated the excellent precision of the closed-loop stiffness and the very wide range of tunings achievable by the system thus controlled. The closed-loop damping tuning is less precise mainly because, as a dynamic phenomenon, its performances are more deteriorated by the uncertainties such as the servovalve non modeled response time. Still a qualitative tuning can be achieved over a reasonable range.

Those results demonstrate that electro-pneumatic cylinders can be an excellent choice when realtime tuning of the closedloop stiffness is needed, and therefore are good candidates in robotic or medical applications. Moreover, it has been shown that electro-pneumatic cylinders combine advantages from both active and passive VSAs: if the closed-loop and pneumatic stiffness are set to the same value, then the system acts as a passive compliant actuator and energy consumption is widely reduced. On the other hand, since the pneumatic stiffness range is limited, the closed-loop stiffness can be chosen far greater or smaller. In this case, the servovalves will ensure that the system respects the specified closed-loop behavior.

Future works will involve the development of SISO control laws, using a single $5 / 2$ servovalve for even more cost effective applications requiring tuning of the closed-loop stiffness. The actual robustness of the system towards bounded external forces could also be studied. A specific system-oriented study has to be conducted to better understand the influence of the servovalves and cylinder sizing over the performances to be expected in terms of closed-loop behavior. Finally, a similar approach could be applied to electro-hydraulic actuators in order to design VSAs able to withstand much larger external forces.

\section{ACKNOWLEDGMENT}

This research was supported by the french National Centre for Space Studies (CNES) and the french National Centre for Scientific Research (CNRS).

\section{REFERENCES}

[1] R. Ham, T. Sugar, B. Vanderborght, K. Hollander, and D. Lefeber, "Compliant actuator designs," Robotics Automation Magazine, IEEE, vol. 16, no. 3, pp. 81-94, 2009.

[2] J. Shearer, Study of pneumatic processes in the continuous control of motion with compressed air. Trans. Am. Soc. Mech. Engrs, 1956, vol. 78, pp. 233-249.

[3] X. Brun, M. Belgharbi, S. Sesmat, D. Thomasset, and S. Scavarda, "Control of an electropneumatic actuator: comparison between some linear and non-linear control laws," in Proceedings of the Institution of Mechanical Engineers, Part I: Journal of Systems and Control Engineering, vol. 213, no. 5. Sage Publications, 1999, pp. 387-406. 
[4] T. F. T. Kimura, S. Hara and T. Kagawa, "Feedback linearization for pneumatic actuator systems with static friction," Control Engineering Practice, vol. 5, no. 10, pp. 1385-1394, 1997.

[5] M. Smaoui, X. Brun, and D. Thomasset, "A combined first and second order sliding mode approach for position and pressure control of an electropneumatic system," in American Control Conference, 2005. Proceedings of the 2005, june 2005, pp. 3007-3012 vol. 5.

[6] A. Estrada and F. Plestan, "Second order sliding mode output feedback control with switching gainsapplication to the control of a pneumatic actuator," Journal of the Franklin Institute, vol. 351, no. 4, pp. 2335 - 2355, 2014, special Issue on 2010-2012 Advances in Variable Structure Systems and Sliding Mode Algorithms. [Online]. Available: http://www.sciencedirect.com/science/article/pii/S0016003213002846

[7] M. Smaoui, X. Brun, and D. Thomasset, "A study on tracking position control of an electropneumatic system using backstepping design," Control Engineering Practice, vol. 14, no. 8, pp. 923-933, 2006.

[8] D. Schindele and H. Aschemann, "Adaptive friction compensation based on the lugre model for a pneumatic rodless cylinder," in Industrial Electronics, 2009. IECON '09. 35th Annual Conference of IEEE, Nov 2009, pp. 1432-1437.

[9] S. Laghrouche, F. S. Ahmed, and A. Mehmood, "Pressure and friction observer-based backstepping control for a vgt pneumatic actuator," Control Systems Technology, IEEE Transactions on, vol. 22, no. 2, pp. 456-467, 2014.

[10] X. Shen and M. Goldfarb, "Simultaneous force and stiffness control of a pneumatic actuator," Journal of Dynamic Systems, Measurement, and Control, vol. 129, no. 4, pp. 425-434, 2007. [Online]. Available: http://link.aip.org/link/?JDS/129/425/1

[11] B. Taheri, D. Case, and E. Richer, "Force and stiffness backsteppingsliding mode controller for pneumatic cylinders," Mechatronics, IEEE/ASME Transactions on, vol. PP, no. 99, pp. 1-11, 2014.

[12] F. Abry, X. Brun, S. Sesmat, and E. Bideaux, "Non-linear position control of a pneumatic actuator with closed-loop stiffness and damping tuning," in Decision and Control, 2013 European Control Conference. ECC, jul. 2013, pp. 4385-4390.

[13] H. Jebar, "Design of pneumatic actuator systems," Ph.D. dissertation, University. Of Nottingham, 1977.

[14] A. Chitty and T. Lambert, "Modelling a loaded two-way pneumatic actuator," Journal of Dynamic Systems Measurements and Control, vol. 9, no. 1, pp. 19-25, 1976.

[15] A. Tustin, "The effect of backslash and speed-dependent friction on the stability of closed-cycle control systems," Journal of the institution of electrical engineers, vol. 94, no. 2A, pp. p143-151, 1947.

[16] W. Leonhard, Control of electrical Drives, corrected 2nd printing ed. Berlin Springer-Verlag, 1990.

[17] M. Krstic, I. Kanellakopoulos, and P. V. Kokotovic, Nonlinear and adaptive control design. Wiley, 1995.

[18] T. Yoshizawa, "Stability theory by lyapunov's second method," The mathematical Society of Japan, no. 9, p. 223, 1966.

[19] S. Laghrouche, M. Smaoui, X. Brun, and F. Plestan, "Robust second order sliding mode controller for electropneumatic actuator," in American Control Conference, 2004. Proceedings of the 2004, vol. 6, 30 2004-july 2 2004, pp. 5090-5095 vol.6.

[20] A. Girin, F. Plestan, X. Brun, and A. Glumineau, "High-order slidingmode controllers of an electropneumatic actuator: Application to an aeronautic benchmark," Control Systems Technology, IEEE Transactions on, vol. 17, no. 3, pp. 633-645, may 2009.

[21] A. Girin and F. Plestan, "A new experimental test bench for a high performance double electropneumatic actuator system," in American Control Conference, 2009. ACC '09., 2009, pp. 3488-3493.

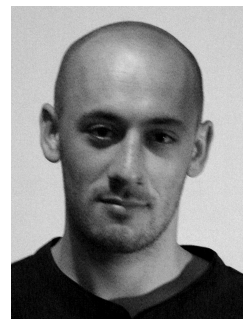

Frédéric Abry was born in France in 1985. He received the M.S. degree in electrical and control engineering. He graduated with a PhD from INSA Lyon Scientific and Technical University in 2013 in non-linear control engineering applied to fluid power systems. Since 2014 he is temporary assistant professor at Ampere Lab UMR CNRS 5005.

His current research interests include control and observation of electrical and fluid power systems and robust real time differentiation.

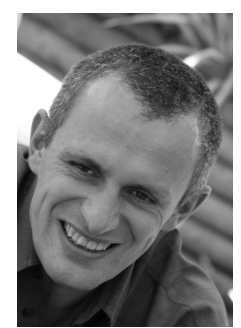

Xavier Brun was born in France in 1973. He is a $\mathrm{PhD}$ graduate from INSA Lyon Scientific and Technical University in 1999. In 2001, Dr Brun became associate professor at Laboratoire d'Automatique Industrielle (LAI) in INSA, France. Since 2011 Dr Brun is professor at Ampere Lab UMR CNRS 5005 and head of the Automatic Control and Mechatronic Team.

His current interests include control for mechatronic and fluid power systems.

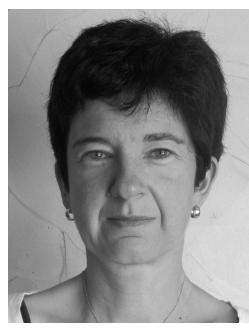

Sylvie Sesmat was born in France in 1967. She is a $\mathrm{PhD}$ graduate from INSA Lyon Scientific and Technical University in 1996. She is currently research engineer at Ampere Lab UMR CNRS 5005.

Her current interests include modeling and characterization of fluid power systems.

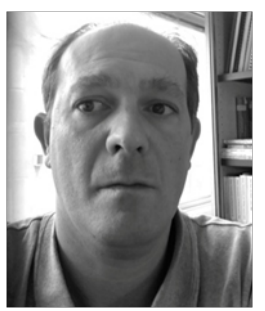

Eric Bideaux received a Mechanical Engineering degree from Ecole Centrale de Nantes, and a PhD. in Automation and Control from the University of Franche-Comt. In 1995, he joined INSA Lyon Scientific and Technical University as assistant professor since 2006 and has now a professor position at the Laboratoire Ampre.

His research fields are control engineering applied to mechatronic and Fluid Power systems with a focus on Bond Graph formalism for modeling, simulation and design of energy efficient systems.

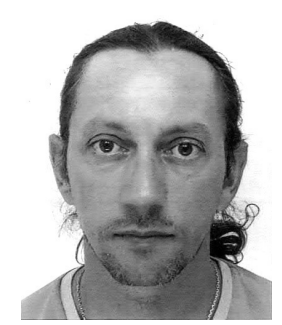

Christophe Ducat received the B.S. degree in mechanical engineering and production automation. From 1997 to 2013 he is mechanical technician in Ampere Lab UMR CNRS 5005. Since 2013 he is a mechanical engineer at CETHIL Lab UMR 5008.

His current interests include mechanical design and production of test benches and prototypes. 